\title{
Challenge of monitoring cohesive movement in homing fish using fine-scale 3D positioning
}

\author{
Junichi Takagi ${ }^{1,5, *}$, Kotaro Ichikawa ${ }^{2,3}$, Nobuaki Arai $^{2,3,6}$, Jun Shoji ${ }^{4}$, Hiromichi \\ Mitamura $^{1,7,8}$
}

\footnotetext{
${ }^{1}$ Graduate School of Informatics, Kyoto University, Yoshida-honmachi, Sakyo-ku, Kyoto 606-8501, Japan

${ }^{2}$ Field Science Education and Research Center, Kyoto University, Oiwake-cho, Kitashirakawa, Sakyo-ku, Kyoto 606-8502, Japan

${ }^{3}$ Graduate School of Agriculture, Kyoto University, Oiwake-cho, Kitashirakawa, Sakyo-ku, Kyoto 606-8502, Japan

${ }^{4}$ Marine Biological Research Institute of Japan, Yutaka, Shinagawa, Tokyo 142-0042, Japan

${ }^{5}$ Present address: National Institute of Polar Research, Midori-cho, Tachikawa-shi, Tokyo, 190-8518, Japan

${ }^{6}$ Present address: National Fisheries University, Nagata-Honmachi, Shimonoseki 759-6595, Japan

${ }^{7}$ Present address: Field Science Education and Research Center, Kyoto University, Oiwake-cho, Kitashirakawa, Sakyo-ku, Kyoto 606-8502, Japan

${ }^{8}$ Present address: Graduate School of Agriculture, Kyoto University, Oiwake-cho, Kitashirakawa, Sakyo-ku, Kyoto 606-8502, Japan
}

\begin{abstract}
Rockfish, which are well known for their site fidelity and homing ability, live sympatrically with many conspecifics. Conspecifics may be external drivers influencing rockfish movement, and rockfish may move cohesively while travelling. We tested whether rockfish formed a group when returning to their original habitat after artificial displacement and examined the routes they travelled to return home. A fine-scale multi-individual simultaneous positioning method was used to observe the movement trajectories of tagged fish. Our results showed that tagged fish, released in groups, returned to their original habitat ( 5 of 8 fish) but generally did not travel with other individuals. There was one exception in which 2 individuals moved together for $\sim 100 \mathrm{~s}$ immediately after release. These 2 fish had no designated leader, alternating as leader and follower. Our hypothesis was partially corroborated by these rockfish possibly travelling cohesively. The returning fish tended to travel along the sea bottom and the coastline, independent of current; thus, they likely used visual cues, rather than olfactory or social cues, to return home.
\end{abstract}

KEY WORDS: Biotelemetry $\cdot$ Homing behaviour $\cdot$ Black rockfish $\cdot$ Sebastes $\cdot$ Schooling behaviour

\section{INTRODUCTION}

Organisms live in groups on diverse spatial and temporal scales. Living in groups provides various advantages (Krause \& Ruxton 2002, Sumpter 2010), such as increasing food search efficiency (Pitcher et al. 1982), reducing predation risk (Partridge 1982, Magurran 1990), and saving locomotion energy (Por-

\footnotetext{
${ }^{*}$ Corresponding author: takagi.junichi.34w@kyoto-u.jp
}

tugal et al. 2014, Hemelrijk et al. 2015, Marras et al. 2015). Navigational ability enhancement is also an advantage of group movement. For example, pigeons home more efficiently when travelling in flocks than when flying alone (Biro et al. 2006, Dell'Ariccia et al. 2008), and king penguin chicks return to their places of origin more efficiently when travelling in pairs than when moving alone (Nesterova et al. 2014).

() The authors 2021. Open Access under Creative Commons by Attribution Licence. Use, distribution and reproduction are unrestricted. Authors and original publication must be credited. 
Navigational ability in anadromous and catadromous fish, such as salmonids (Ueda 2012) and eels (Baltazar-Soares \& Eizaguirre 2017), has also been well documented. However, most animal-position studies investigating the relationship between cohesive movement and navigational ability have focussed on terrestrial animals. Research on navigation in schooling fish is scarce, although cohesive behaviour is well documented in homing fish, such as salmonids. Berdahl et al. (2016) found strong evidence for collective navigation in salmonids and that the rates of successful homing increase with population abundance. Although their study approached large-scale navigation, it was not based on empirically acquired movement data such as GPS, making it difficult to directly examine navigational mechanisms. In another study, orientation ability after translocation away from the reef was compared between shoaling fish larvae and isolated individuals (Irisson et al. 2015). However, this previous study used only $10 \mathrm{~min}$ of observation data following release, which did not cover the entire distance travelled towards the goal.

A problem preventing the acquisition of detailed navigation information for schooling fish in the wild is that these animals undergo wide-ranging migrations. Salmonids and eels perform trans-oceanic navigation to natal rivers or marine areas (Ueda 2012, Baltazar-Soares \& Eizaguirre 2017). These migration routes are too vast to be observed in their entirety. For example, although eels have been monitored across their oceanic spawning migrations using electric tags (Righton et al. 2016), existing telemetry tools do not allow for the collection of data sufficiently high in resolution to study fine-scale navigation. However, translocation of a species exhibiting shortrange homing would allow for the collection of highresolution movement data required to investigate collective navigation.

Rockfish of the genus Sebastes exhibit strong site fidelity and homing ability after artificial displacement (Matthews 1990a, Reynolds et al. 2010, Green \& Starr 2011). The black rockfish $S$. cheni inhabits rocky areas and maintains small home ranges (Harada 1962, Mitamura et al. 2009). This species navigates back to its original habitat, even after artificial displacement of 1-4 km (Mitamura et al. 2002). Individuals predominantly use olfaction to return home from unfamiliar areas (Mitamura et al. 2005, 2012), while they also use vision in familiar areas (Mitamura et al. 2012). Juvenile black rockfish form large shoals, whereas the adults tend to be solitary and seldom form groups (Harada 1962). However, there is no clear evidence as to whether they move in schools.
In the framework of movement ecology, external factors (biotic and abiotic), internal state, motion capacity, and navigational capacity all influence movement (Nathan et al. 2008). The presence of conspecifics as an external factor can influence the movement of individuals (Delgado et al. 2014). In our preliminary release experiment, several black rockfish started to move in groups of 2-5 individuals after 16 individuals were simultaneously released, although their body size was smaller than the individuals used in the biotelemetry experiment of the present study (see Video S1 in the Supplement at www. int-res.com/articles/suppl/b030p033_supp/). Furthermore, black rockfish are not territorial outside of their mating season (Shinomiya \& Ezaki 1991; October to January, which was beyond the period assessed in the current study); thus, these fish likely tolerate conspecifics. If black rockfish recognise conspecifics visually and/or using other senses, their movements might, at least partially, be motivated by these other individuals, following which collective navigation could be practised. Therefore, adult black rockfish released after artificial displacement away from their home range in a group could move together using social cues from conspecifics during their homing journey.

Biotelemetry techniques using transmitters and receivers have been widely used to monitor the movement of aquatic animals by hyperbolic positioning based on time-difference-of-arrival (TDOA; e.g. Espinoza et al. 2011, Biesinger et al. 2013, Wolfe \& Lowe 2015). Recently, several biotelemetry systems have become available to simultaneously localise multiple individuals at short intervals of a few dozen seconds with sub-metre accuracy (e.g. Guzzo et al. 2018, Leclercq et al. 2018), which is not possible with conventional biotelemetry systems. Previously, we also developed a fine-scale simultaneous positioning method for multiple individuals that locates several fish in 3 dimensions at intervals of $<10 \mathrm{~s}$ with a precision of $<0.1 \mathrm{~m}$ (Takagi et al. 2018). This positioning method allows us to monitor the entire route travelled by multiple fish during short-range homing.

Here, we propose the hypothesis that sympatric fish with high site fidelity, released with conspecifics, form a group while returning to their original habitat after artificial displacement. Conversely, the null hypothesis is that the fish will travel alone (without forming a group) during their return. Our objectives were to test the hypothesis using black rockfish, and to investigate how black rockfish return to their place of origin. While group behaviour (i.e. the coordinated movement of wild animals) has attracted considerable research attention, its observation has been re- 
stricted by available technological capacity, making it possible to simultaneously monitor multiple animals with high precision in the field, especially underwater. We conducted the study by biotelemetrically observing the trajectories of homing black rockfish using our fine-scale multi-individual simultaneous positioning method.

\section{MATERIALS AND METHODS}

\subsection{Study area and deployed array}

Field experiments were conducted during July 2017 in a shallow $(<20 \mathrm{~m})$ sea area on the east coast of Ikuno Island $\left(34^{\circ} 29^{\prime} \mathrm{N}, 132^{\circ} 92^{\prime} \mathrm{E}\right)$ in the Seto Inland Sea, Japan (Fig. 1). The tidal difference during the experiments was $\sim 3.5 \mathrm{~m}$. A total of 14 receivers (AQRM-1000, AquaSound; 64 mm diameter $\times$ $300 \mathrm{~mm}$ length) were deployed with overlapping detection ranges $(<40 \mathrm{~m})$ on the sea bottom of the

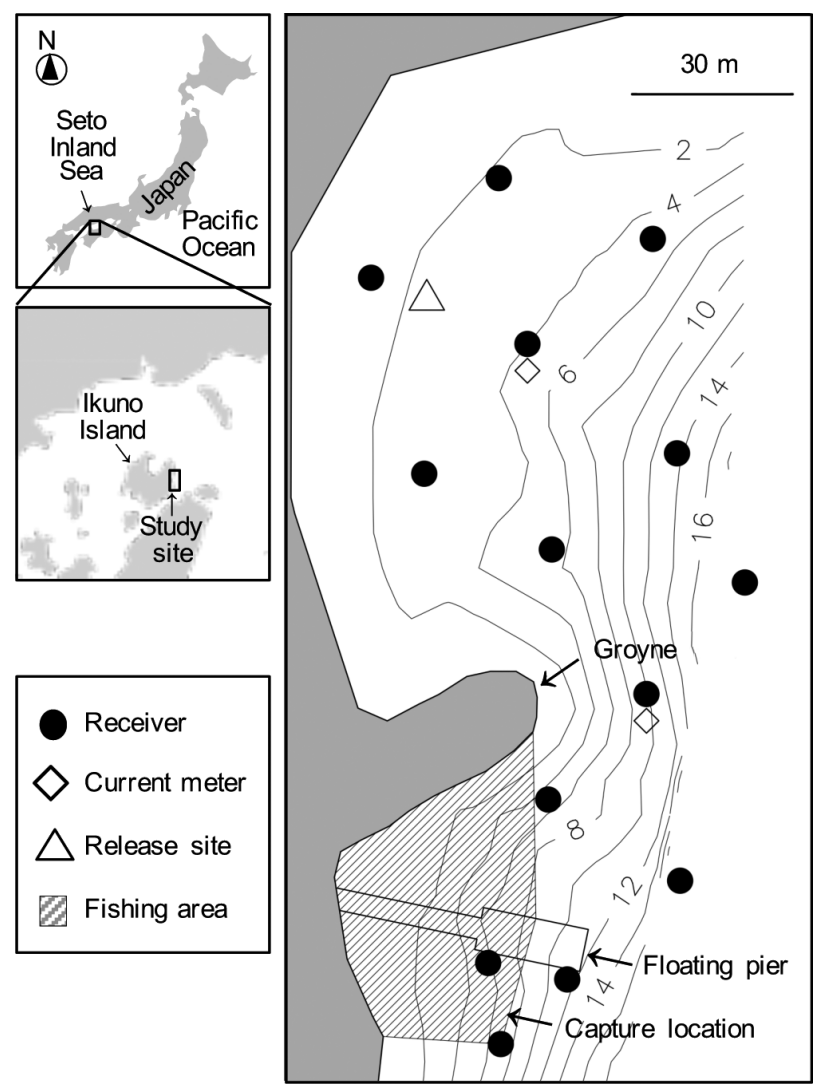

Fig. 1. Acoustic array of 14 receivers deployed off Ikuno Island $\left(34^{\circ} 29^{\prime} \mathrm{N}, 132^{\circ} 92^{\prime} \mathrm{E}\right)$, central Seto Inland Sea, southwestern Japan. Two current meters were deployed near the release site and the fishing area. The black rockfish used in this study were caught in the fishing area around the floating pier. Lines along the coastline: depth contours (m) study area (Fig. 1). To synchronise the internal clocks of the receivers, one Gold code transmitter (AQTD600P, AquaSound; $27 \mathrm{~mm}$ diameter $\times 130 \mathrm{~mm}$ length; sound pressure level: $160 \mathrm{~dB}$ re $1 \mu \mathrm{Pa}$ at $1 \mathrm{~m}$; transmitting interval: $60 \mathrm{~s}$ ) was placed on every receiver, except one on the west side of the floating pier, as shown in Fig. 1. The Gold codes used in the transmitter signals were one of the pseudo-noise codes in a pair of M-sequences with low cross-correlation among codes (Gold 1967). The positional precision of the biotelemetry system used was $<0.1 \mathrm{~m}$ (Takagi et al. 2018). For positioning, the algorithm outputs a position localised using 3 receivers judged to be the nearest to the position of a sound source (i.e. a transmitter emitting a signal) in the shape of an equilateral triangle. Once a signal is detected by the nearest 3 receivers, the positional precision should be similar because it was theoretically determined by shapes of a triangle and the temporal resolution of the biotelemetry system $\left(10^{-6} \mathrm{~s}\right)$ to sound speed. Thus, we deployed 14 receivers in the shape of an equilateral triangle as precisely as possible, although local geographical features prevented a perfect arrangement (Fig. 1). We set shorter distance between the receivers (25.6 $\mathrm{m}$ on average; range: $15.1-30.5 \mathrm{~m}$ ) than that of Takagi et al. (2018) ( 75 m) to enable signal detection by 3 or more receivers.

The electromagnetic current meters (INFINITYEM, JFE-Advantech; direction range: $0-360^{\circ}$; resolution: $0.01^{\circ}$; accuracy: $\pm 2^{\circ}$; speed resolution: $0.02 \mathrm{~cm}$ $\mathrm{s}^{-1}$; speed accuracy: $\pm 1 \mathrm{~cm} \mathrm{~s}^{-1}$ or $\pm 2 \%$ ) were programmed in 'burst mode' to record current direction and speed (a single datum every 3 min with an average of 30 successive data points at $1 \mathrm{~s}$ intervals). The current meters were deployed at 2 points on the sea bottom. One of these points was near the release point and the other was near the fishing site in an area through which the tagged fish had to pass during their homing journey (Fig. 1).

\subsection{Tagging and releasing fish}

Black rockfish $(\mathrm{n}=8$; mean $\pm \mathrm{SD}$ total length [TL]: $20.9 \pm 1.4 \mathrm{~cm}$; body weight [BW]: $151.4 \pm 30.2 \mathrm{~g}$; see Table 1) were captured using baited hooks and lines around the floating pier (Fig. 1). Fishing positions relative to the floating pier were recorded. The rockfish were labelled with dart tags (each $\sim 30 \mathrm{~mm}$ in length; Hallprint Fish Tags) for identification. Since it was difficult to collect more than a few large black rockfish (>19 cm) simultaneously, we attempted to capture fish several times between 12 May and 1 July 
2017. Specimens were kept in a $\sim 6001$ round tank ( 1280 mm diameter, $815 \mathrm{~mm}$ height, $1000 \mathrm{l}$ volume) for 5-55 d until the experiment started. The tank was supplied with fresh seawater flowing at a rate of $\sim 101 \mathrm{~min}^{-1}$. Black rockfish generally exhibit the ability to home to their original habitats several months after capture (Mitamura et al. 2005). Therefore, the comparatively brief stocking period of this study likely had no significant influence on rockfish homing ability. Gold code transmitters with depth sensors (AQPX-1030P, AquaSound Inc; $9.5 \mathrm{~mm}$ in diameter, $36 \mathrm{~mm}$ in length; sound pressure level: $155 \mathrm{~dB}$ re $1 \mu \mathrm{Pa}$ at $1 \mathrm{~m}$; depth sensor accuracy: $0.5 \mathrm{~m}$; depth sensor resolution: $\sim 0.15 \mathrm{~m}$; transmitting interval: $\sim 2.5$ s) were surgically inserted into the abdominal cavities of the fish under $0.1 \%$ 2-phenoxyethanol anaesthesia. During the operations, the rockfish were placed between layers of bubble wrap in fresh aerated seawater baths. After surgery, the fish were kept in fresh seawater until the anaesthetic wore off.

The 8 tagged fish were separated into 2 groups (G1 or G2) consisting of 4 individuals each (see Table 1). The fish were placed in an inverted transparent container equipped with small holes for water circulation and maintained on the sea bottom ( 2.8 m depth) at a release point inside the array $\sim 110 \mathrm{~m}$ away from the capture point (floating pier in Fig. 1). The release point was assumed to be outside the tagged fish's home ranges because black rockfish generally inhabit rocky areas, whereas the release point was situated on a flat sea bottom with sandy sediment. After $>30$ min acclimation, the container was slowly opened, and the tagged fish were released. The 2 groups were released in the evenings of 3 July 2017 (G1, Expt 1) and 6 July 2017 (G2, Expt 2) because black rockfish are expected to start homing during the night (Mitamura et al. 2009). Their 3D positions were monitored for $\sim 3 \mathrm{~d}$ after release, restricted by the battery life of the transmitters used.

\subsection{Data analysis}

The horizontal and vertical components of the 3dimensional (3D) positions of the rockfish were obtained separately. Horizontal positions were calculated by hyperbolic positioning based on TDOA among 3 or more receivers (Takagi et al. 2018). Vertical positions (swimming depths) were determined using a pressure sensor in the transmitters. Outliers were removed from the position data by 3D speed limitation (10 $\mathrm{TL} \mathrm{s}^{-1}$ in this study). If the speed differential between 2 consecutive data points was $>10$
TL $\mathrm{s}^{-1}$, the latter point was removed. To calculate certain indices for schooling behaviour, such as inter-individual distance, it was necessary to temporally align the position data of each fish. Thus, the position data were spatially interpolated by a linear interpolation algorithm every $2.5 \mathrm{~s}$, which was a little greater than actual transmitting intervals, if there was zero or one missing value between each data step (temporal interval between 2 consecutive data points < 5 s). The $2.5 \mathrm{~s}$ interpolated position data were subsequently used in the analysis. Positioning was performed in Matlab R2017a (The Math Works).

Individuals that had site fidelity to the fishing area were defined as returning individuals and were identified as those that returned to the fishing area around the floating pier where they were captured (area: $1520.4 \mathrm{~m}^{2}$; Fig. 1) and remained there for $1 \mathrm{~h}$. The home ranges of the tagged fish were then estimated to establish whether their release points were outside their home ranges and the fishing area was inside their home ranges. The 95 and 50\% home range areas were calculated by kernel density estimation with the 'adehabitatHR' package for $\mathrm{R}$ v.3.4.2 (R Core Team 2017). In each estimation, bandwidth was respectively calculated as 'reference bandwidth' $(=h)$ by that package based on the positions provided. Position data following sunrise on the day after release (05:03 h on 4 July 2017 or 05:05 h on 7 July 2017) were used for the estimation to exclude the influence of displacement. Interindividual distances were calculated to determine whether the tagged fish travelled together. The straightness index (Batschelet 1981) was employed to measure the linearity of a travelling path, which was computed by dividing beeline distance from the release point to a goal point by the distance travelled. For returning individuals, a goal point was the last point of their returning journeys, while for non-returning individuals, it was the last position localized or the first position localized in its 95\% home range area. The distance travelled and travel time periods were calculated from release to the goal point.

The movements of individuals in pairs were determined from instantaneous inter-individual distances and trajectories. To express collective fish movement, dynamic interaction ( $d i_{i}$ Long \& Nelson 2013) was calculated on a $2 \mathrm{D}$ plane. The di measures collectiveness between pairs of moving objects using the Euclidian distances (step length) and azimuths (movement direction) between 2 consecutive positions. It was determined as follows: 


$$
\begin{gathered}
d i=f_{t}\left(v_{t}^{a}, v_{t}^{b}\right)=d i_{\theta} \times d i_{d} \\
d i_{\theta}=g_{t}\left(\theta_{t}^{a}, \theta_{t}^{b}\right)=\left\{\begin{array}{cc}
0 & \text { one of } \theta_{t}^{a} \text { or } \theta_{t}^{b} \text { undefined } \\
1 & \text { both } \theta_{t}^{a} \text { and } \theta_{t}^{b} \text { undefined } \\
\cos \left(\theta_{t}^{a}-\theta_{t}^{b}\right) & \text { otherwise }
\end{array}\right. \\
d i_{d}=h_{t}\left(d_{t}^{a}, d_{t}^{b}\right)=\left\{\begin{array}{cc}
1, & d_{t}^{a}+d_{t}^{b}=0 \\
1-\left(\frac{\left|d_{t}^{a}-d_{t}^{b}\right|}{d_{t}^{a}+d_{t}^{b}}\right)^{\alpha}, & d_{t}^{a}+d_{t}^{b}>0
\end{array}\right.
\end{gathered}
$$

where $v$ is the vector, $\theta$ is the angle of movement, $d$ is the Euclidian distance, $|\bullet|$ is the absolute value operator, $\alpha$ is the scaling parameter (set to 1 in this study), superscript $a$ or $b$ means the moving object $a$ or $b$, subscript t means a given time step $t$, and $f(\bullet), g(\bullet)$, and $h(\bullet)$ mean functions. Using this definition, both $d i_{\theta}$ and $d i_{d}$ have a range of $[-1,1]$. Therefore, di has the same range. Positive values of $d i$ correspond to cohesive or positive interactive movements, while negative values are interpreted as repulsive or opposing movements. Values near zero mean no interaction. In addition, to evaluate the former position of each fish in relation to each of the other fish in the direction of travelling, the positional relationship $(P R)$ index of the pair was defined as follows:

$$
P R=\left(\frac{d_{\text {dir }}}{d_{\text {int }}}\right)^{2}, d_{\text {int }}>0
$$

where $d_{\text {int }}$ is the inter-individual distance (i.e. the distance between the pair of fish at a particular time) and $d_{\text {dir }}$ is the inter-individual distance in the movement direction that was calculated using the Euclidian distances (step length) and azimuths (movement direction) between 2 consecutive positions of the pair of fish. $P R$ has a range of $[0,1]$. Values near 1 mean that either one of the pair moves behind the other, whereas values near zero mean that the pair moves side by side.

To consider the homing behaviour of the tagged fish, we examined their homing routes in relation to current direction, and bottom and swimming depth. First, we investigated the movement directions on a 2D plane of every fish relative to the current immediately after release (inside the bay) and on the way to the fishing area (outside the bay). To determine current direction, the null hypothesis that the direction is uniformly distributed was evaluated using the Rayleigh test in $\mathrm{R}$ v.3.4.2. Movement directions for the trajectories of every fish were visually determined. Second, associations between swimming depth and bottom depth along the routes of the homing individuals were investigated. The bottom depth was derived from depth contour data. The swimming depth range was defined as the distance between the tagged fish and the sea bottom at any point, i.e. bottom depth minus swimming depth.

\subsection{Preliminary release experiment}

Fish were captured using baited hooks and lines at the floating pier (Fig. 1) and kept in a container $(42.5 \times 71.6 \times 32.3 \mathrm{~cm})$ equipped with small holes for water circulation under the sea for a few days. TL $(\sim 15-18 \mathrm{~cm})$ was approximated by eye. The fish were moved to an inverted transparent container on the sea bottom ( 1.0 m depth) along the coastline $\sim 30 \mathrm{~m}$ north of the groyne (Fig. 1). For release, the container was opened slowly, and the 16 tagged fish were released at 10:55 h on 14 May 2017. The fish were observed by snorkelling and video camera filming.

\section{RESULTS}

\subsection{Cohesive movement}

We obtained movement trajectories for the 8 tagged black rockfish (Fig. 2). According to their inter-individual distances (Fig. 3) and movement trajectories (Fig. 2), there were 2 individuals that travelled together immediately after release in Expt 1. G1-3 and G1-4 travelled together for $\sim 100 \mathrm{~s}$ after release (Fig. 4). G1-4 started to move $\sim 30$ s after release, while G1-3 followed later and eventually caught up with G1-4. They then swam synchronously along the sea bottom for $\sim 50 \mathrm{~s}$. Their $d i$ was very high (near unity) (Fig. $4 \mathrm{~F}$ ). During synchronous movement, the leader and follower traded places several times (Fig. 4F,G). Since the $P R$ was near zero, they travelled side-by-side for the majority of the period they were swimming together (Fig. 4G). After a separation, G1-3 changed direction and returned to the fishing area (Fig. 2), whereas G14 settled in one place for a while after it was separated from G1-3 and then left the receiver array (Fig. 2). The remaining tagged black rockfish did not travel with other individuals for most of their journey. After separating, they remained about 5-70 $\mathrm{m}$ apart (Fig. 3).

In the preliminary release experiment, 10 of the 16 fish began moving in groups of 2, 3, and 5 individuals, while 4 fish began moving alone (Video S1). The remaining 2 fish stayed around the release point at least for $13 \mathrm{~min}$ after release. The fish moving together started to move towards northeast one after another, following the other fish. Two of the 4 fish moving alone headed towards the east, while the other 2 fish headed towards the northeast. 


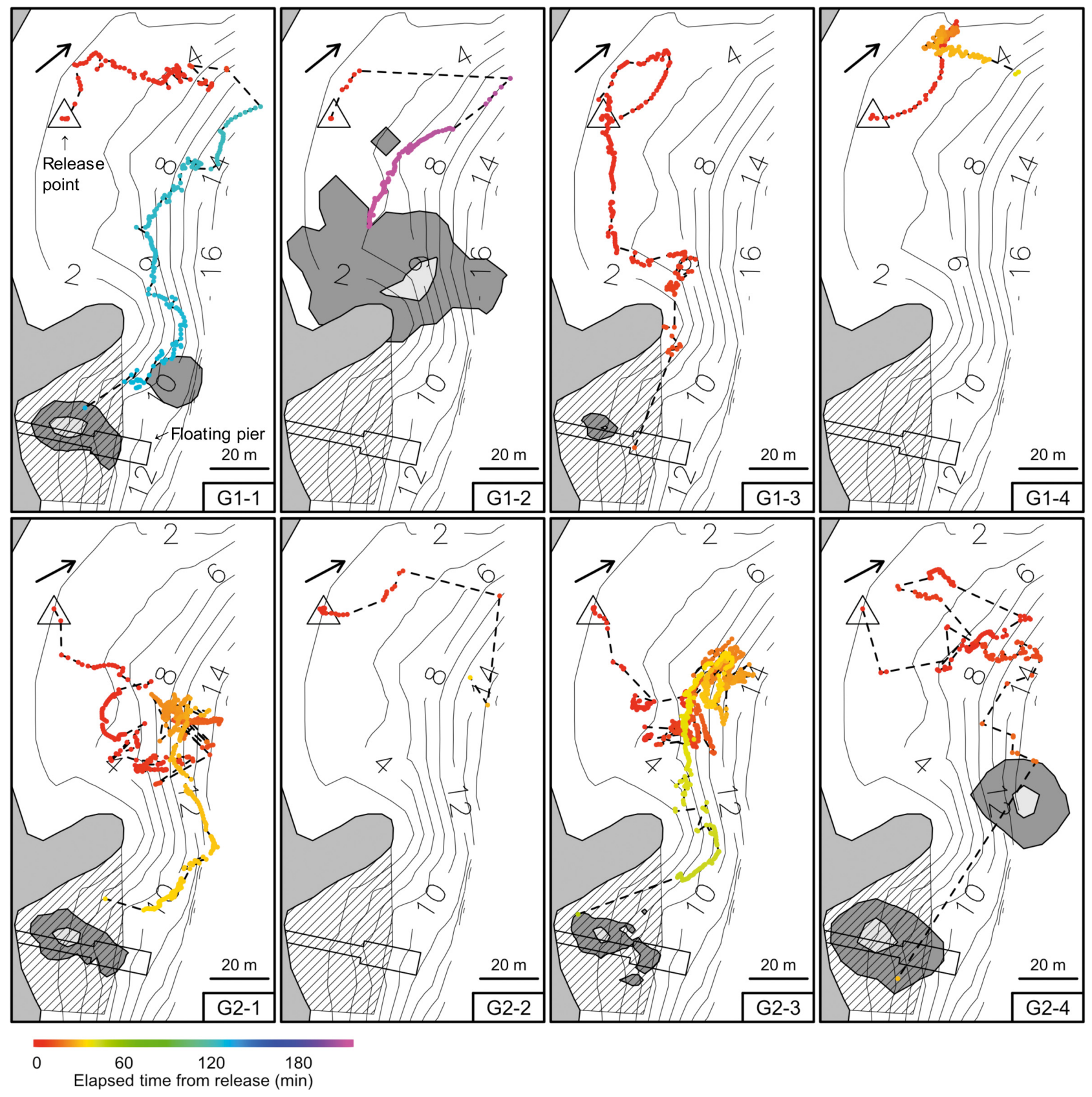

Fig. 2. Travelling routes and/or home ranges of 8 tagged black rockfish. G1-1, G1-2, G1-3, and G1-4 were released simultaneously, as were G2-1, G2-2, G2-3, and G2-4. Cross-hatched area around the floating pier: home area where tagged rockfish were captured. Dark and light grey shading: 95 and $50 \%$ home ranges, respectively; dotted lines with coloured dots: homing routes (G1-1, G1-3, G2-1, G2-3, and G2-4), or localised positions to the 95\% home range area (G1-2), or all localised positions before leaving the receiver array (G1-4, and G2-2). The doted lines indicate interpolations during periods with no positioning data. Different colours indicate elapsed time from release. Black arrow at the upper left in each pane: current direction around release site at release time

\subsection{Homing behaviour}

Five of the 8 tagged black rockfish successfully returned to the fishing area the night of release (Fig. 2, Table 1). In the 2 experiments, 2 (G1-1 and
G1-3) and 3 (G2-1, G2-3, and G2-4) of the 4 individuals returned to the fishing area (Fig. 2, Table 1). The remaining 3 fish did not return to the fishing area. Two of those individuals (G1-4 and G2-2) left the receiver array: G1-4 travelled $272.3 \mathrm{~m}$ for $39.9 \mathrm{~min}$ 

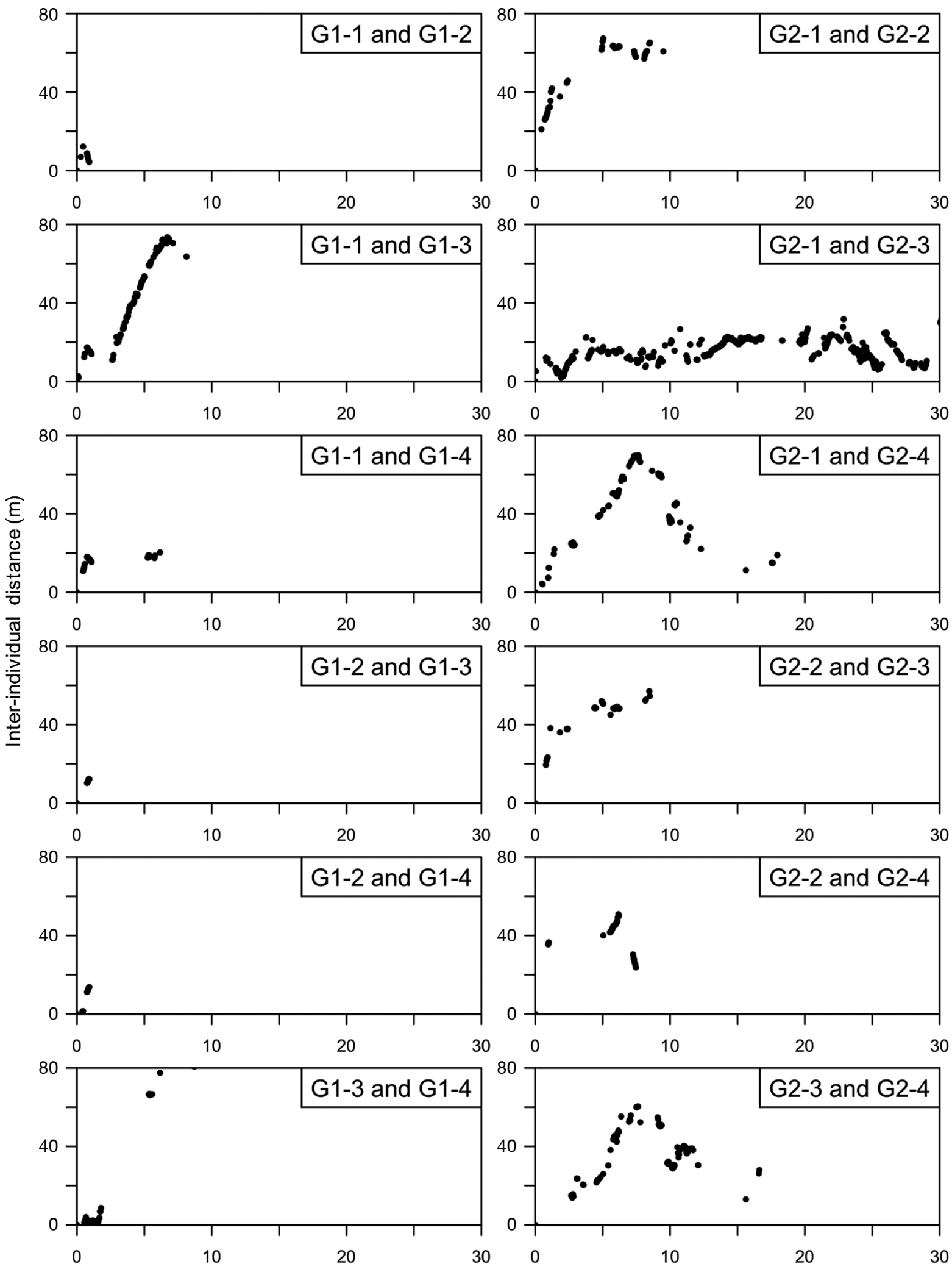

Elapsed time from release $(\mathrm{min})$

Fig. 3. Inter-individual distances of tagged black rockfish for $30 \mathrm{~min}$ after release. For example, the graph titled 'G1-1 and G1-2' shows the time series distance between fish G1-1 and fish G1-2, which were released simultaneously in the G1 group 

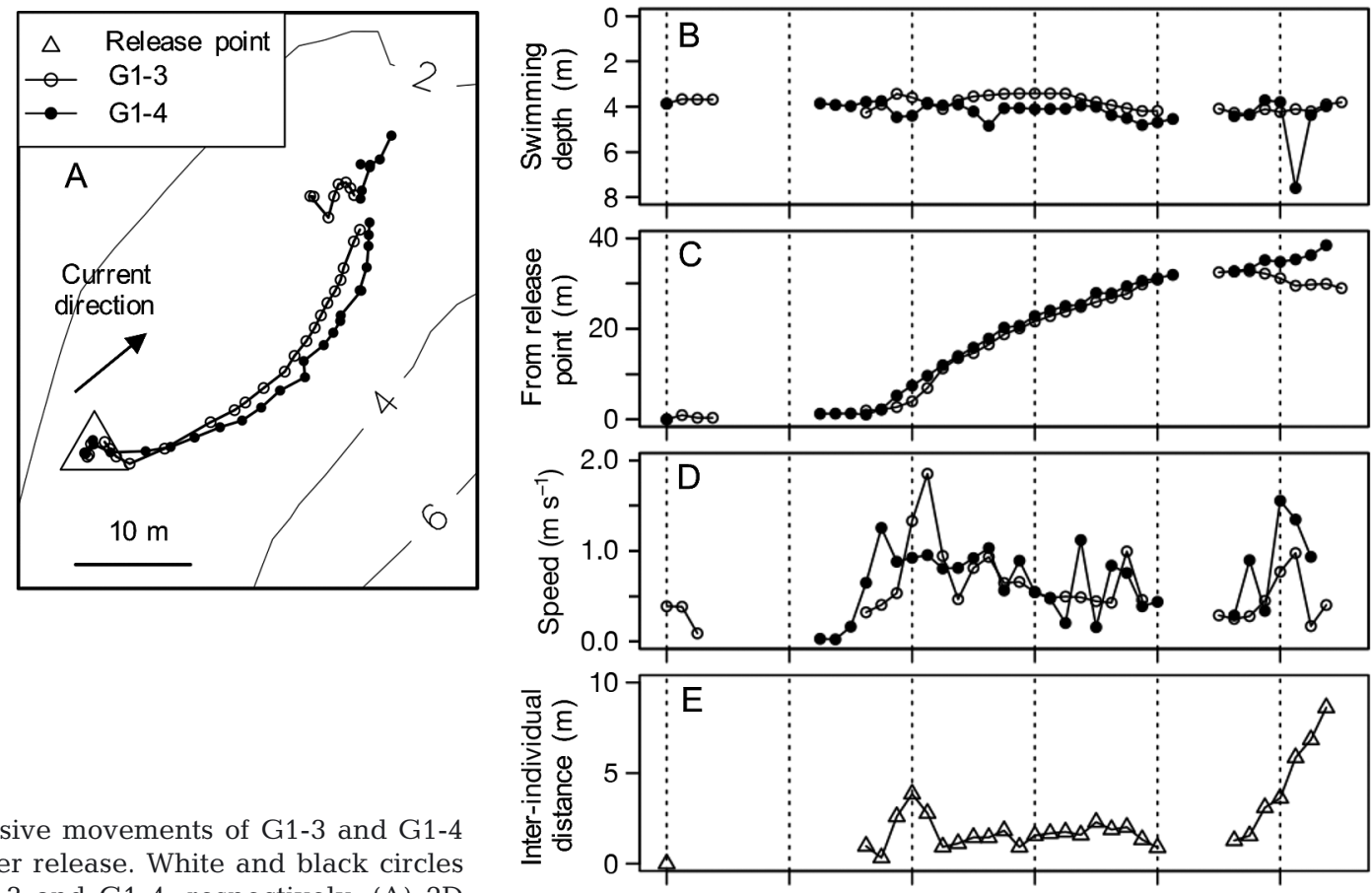

4. Cohesive movements of G1-3 and G1 for $110 \mathrm{~s}$ after release. White and black circles indicate G1-3 and G1-4, respectively. (A) 2D positions. Thin lines: 2, 4, and $6 \mathrm{~m}$ depth contours. (B) Swimming depth; (C) distance from release point; (D) 3D movement speed; (E) 2D inter-individual distance; (F) dynamic interaction between 2 fish. Positive values: cohesive or positive interactive movements; negative values: repulsion or opposing movements; values near zero: no interaction. (G) Positional relationship between 2 fish. Values near 1: one of the pair travels behind the other; values near zero: the pair travels side-by-side. In (F) and (G), the white and black circles indicate that either G1-3 or G1-4, respectively, is leading the other in the movement direction

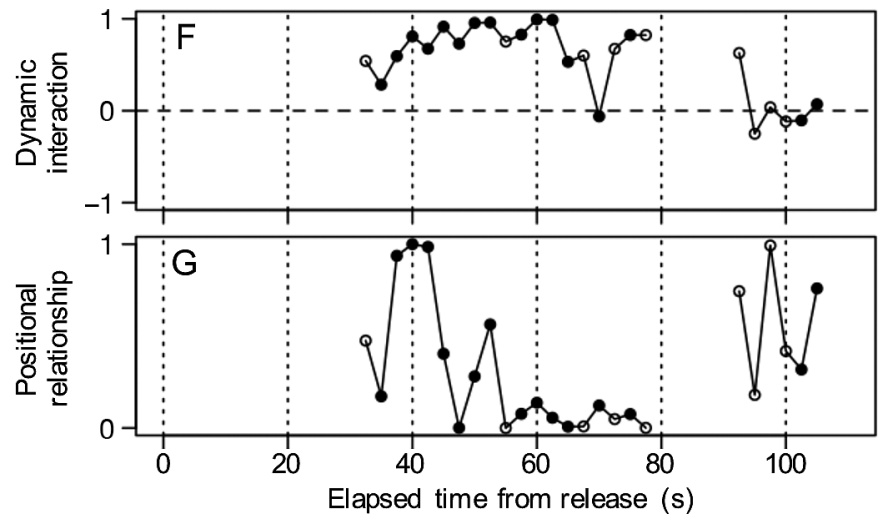

Table 1. Descriptive characteristics and summary of travelling for tagged black rockfish Sebastes cheni. Tagged fish were released in 2 groups, each consisting of 4 individuals, indicated as G1 or G2. G1 fish were released on 3 July 2017, and G2 fish on 6 July 2017. 'Fishing place' indicates relative direction and approximate distance from floating pier (close: 0-5 m, middle: 5-15 m, far: $>15 \mathrm{~m}$ ). Individuals returning to their capture area are indicated as ' $\mathrm{Y}^{\prime}$; non-returning individuals are indicated as ' $\mathrm{N}$ '. The number of positions obtained, period, and distance travelled were determined from release to goal for individuals returning to their capture area, using all data for individuals leaving the receiver array (G1-4, and G2-2), and from release to home range area for an individual not returning to its capture area (G1-2). 'Straightness index' was calculated by dividing distance from a release to a last point by the distance travelled. n/a: not applicable

\begin{tabular}{|c|c|c|c|c|c|c|c|c|c|c|}
\hline Fish ID & $\begin{array}{c}\text { Total } \\
\text { length } \\
(\mathrm{cm})\end{array}$ & $\begin{array}{c}\text { Body } \\
\text { weight } \\
\text { (g) }\end{array}$ & Fishing place & Returning & $\begin{array}{c}\text { No. of } \\
\text { positions } \\
\text { obtained }\end{array}$ & $\begin{array}{c}\text { Period } \\
\text { (min) }\end{array}$ & $\begin{array}{c}\text { Distance } \\
\text { travelled } \\
\text { (m) }\end{array}$ & $\begin{array}{c}\text { Straight- } \\
\text { ness } \\
\text { index }\end{array}$ & $\begin{array}{l}\text { Release } \\
\text { time }\end{array}$ & Goal time \\
\hline G1-1 & 22.0 & 181.5 & North, middle & $\mathrm{Y}$ & 261 & 133.2 & 425.8 & 0.24 & $18: 24: 10$ & $20: 37: 22.5$ \\
\hline G1-2 & 23.0 & 190.5 & North, far & $\mathrm{N}$ & 112 & 215.1 & 167.5 & 0.24 & & $\mathrm{n} / \mathrm{a}$ \\
\hline G1-3 & 19.5 & 123.5 & North, middle & $\mathrm{Y}$ & 199 & 14.8 & 328.4 & 0.35 & & $18: 39: 00.0$ \\
\hline G1-4 & 19.5 & 119.5 & North, middle & $\mathrm{N}$ & 209 & 39.9 & 272.3 & 0.19 & & $\mathrm{n} / \mathrm{a}$ \\
\hline G2-1 & 21.7 & 165.5 & North, middle & $\mathrm{Y}$ & 676 & 35.9 & 961.1 & 0.11 & $18: 30: 00$ & $19: 05: 53.5$ \\
\hline G2-2 & 20.5 & 156.5 & North, close & $\mathrm{N}$ & 63 & 35.1 & 138.8 & 0.41 & & $\mathrm{n} / \mathrm{a}$ \\
\hline G2-3 & 19.3 & 109.5 & South, middle & $\mathrm{Y}$ & 853 & 49.8 & 1090.8 & 0.10 & & $19: 19: 45.0$ \\
\hline $\mathrm{G} 2-4$ & 22.0 & 164.5 & South, middle & $\mathrm{Y}$ & 148 & 31.1 & 441.7 & 0.29 & & 19:01:08.5 \\
\hline
\end{tabular}


and G2-2 travelled $138.8 \mathrm{~m}$ for $35.1 \mathrm{~min}$ before leaving the array after release (Fig. 2, Table 1). They did not return to the receiver array within the $\sim 3 \mathrm{~d}$ monitoring period. The other individual (G1-2) stayed in the receiver array but outside the fishing area (Fig. 2). There was no localised position of G1-2 in the fishing area. For the 5 returning individuals, the travel duration for return was $53.0 \pm 46.6 \mathrm{~min}(\mathrm{n}=5$ ind.; Table 1$)$ and the distance travelled for return was $649.6 \pm$ $349.3 \mathrm{~m}(\mathrm{n}=5$; Table 1$)$. The straightness index of the 5 fish was $0.22 \pm 0.11(\mathrm{n}=5$; Table 1$)$.

Home ranges were estimated for all but 2 tagged black rockfish (G1-4 and G2-2). These 2 individuals left the receiver array; therefore, their home range areas could not be calculated. The $95 \%$ home range area was $864.3 \pm 833.9 \mathrm{~m}^{2}$ ( $\mathrm{n}=6$ ind.; Table 2). The release point was outside their home ranges. Thus, the tagged fish travelled from an unfamiliar area after their displacement and release (Fig. 2). The home ranges of the 5 returning individuals were within the fishing area. In contrast, that of the single non-returning individual was outside the fishing area (Fig. 2).

In Expt 1, around the release time (18:00-19:00 h) on 3 July 2017, the current was directed towards the northeast near the release point (Table 3). G1-1 and G1-2 moved towards the north, and G1-3 and G1-4 headed northeast (Fig. 2). In Expt 2, around the release time (18:00-19:00 h) on 6 July 2017, the current was not concentrated in any direction around the release site (Table 3). G2-1, G2-3, and G2-4 moved south, while G2-2 headed northeast (Fig. 3). For the homing journey of the 5 individuals, the currents near the fishing area were either directed towards the west (3 July 2017 in Expt 1; and 19:0020:00 h on 6 July 2017 in Expt 2; Table 3) or showed no consistent direction (18:00-19:00 h on 6 July 2017 in Expt 2; Table 3).

The travelling routes of the returning individuals were influenced by geographical features. Horizontally, G1-1, G2-1, and G2-3 swam tortuously until they reached the proximity of the groyne, then swam along the coastline (Fig. 2). G1-3 swam mostly along the coastline after separating from G1-4. This behaviour was unclear in G2-4 due to discontinuity in its travelling route. Vertically, the swimming depth of the returning individuals was associated with the bottom depth. They seemed to keep within the vicinity of the sea bottom (Fig. 5). G1-3, which travelled at about 5-10 m depths, kept within $4 \mathrm{~m}$ of the sea bottom (Table 4). The other 4 individuals, all of which travelled at deeper depths than G1-3, mostly swam within $5 \mathrm{~m}$ of the sea bottom, although there were differences in swimming depth among individuals (Table 4).

Table 3. Mean $( \pm \mathrm{SD})$ current speed $(\mathrm{n}=20)$ and direction at 2 points (near release site/fishing area) during homing of tagged black rockfish. Length: length of the mean vector $(0 \leq \mathrm{r} \leq 1)$. For mean angle, $0^{\circ}$ indicates $\mathrm{N}$, with clockwise rotation. Test statistic is from a Rayleigh test; null hypothesis is that the data are uniformly distributed

\begin{tabular}{|c|c|c|c|c|c|c|c|}
\hline Day & Place & Time (h) & $\begin{array}{c}\text { Current } \\
\text { speed }\left(\mathrm{cm} \mathrm{s}^{-1}\right)\end{array}$ & $\begin{array}{l}\text { Length } \\
\text { (r) }\end{array}$ & $\begin{array}{c}\text { Mean angle } \\
\text { (degrees) }\end{array}$ & $\begin{array}{c}\text { Test } \\
\text { statistics }\end{array}$ & $\mathrm{p}$ \\
\hline \multirow[t]{4}{*}{3 July (Expt 1) } & Near release site & $18: 00-19: 00$ & $2.1 \pm 0.6$ & 0.96 & 51 & 0.96 & $<0.001$ \\
\hline & Near fishing area & $18: 00-19: 00$ & $4.1 \pm 1.8$ & 0.69 & 258 & 0.69 & $<0.001$ \\
\hline & & $19: 00-20: 00$ & $10.1 \pm 6.2$ & 0.95 & 242 & 0.95 & $<0.001$ \\
\hline & & $20: 00-21: 00$ & $21.4 \pm 3.6$ & 1 & 244 & 1 & $<0.001$ \\
\hline \multirow[t]{3}{*}{6 July (Expt 2) } & Near release site & $18: 00-19: 00$ & $3.8 \pm 3.3$ & 0.21 & 62 & 0.21 & $>0.05$ \\
\hline & Near fishing area & $18: 00-19: 00$ & $5.1 \pm 2.6$ & 0.28 & 290 & 0.28 & $>0.05$ \\
\hline & & $19: 00-20: 00$ & $2.7 \pm 1.6$ & 0.39 & 266 & 0.39 & $<0.05$ \\
\hline
\end{tabular}




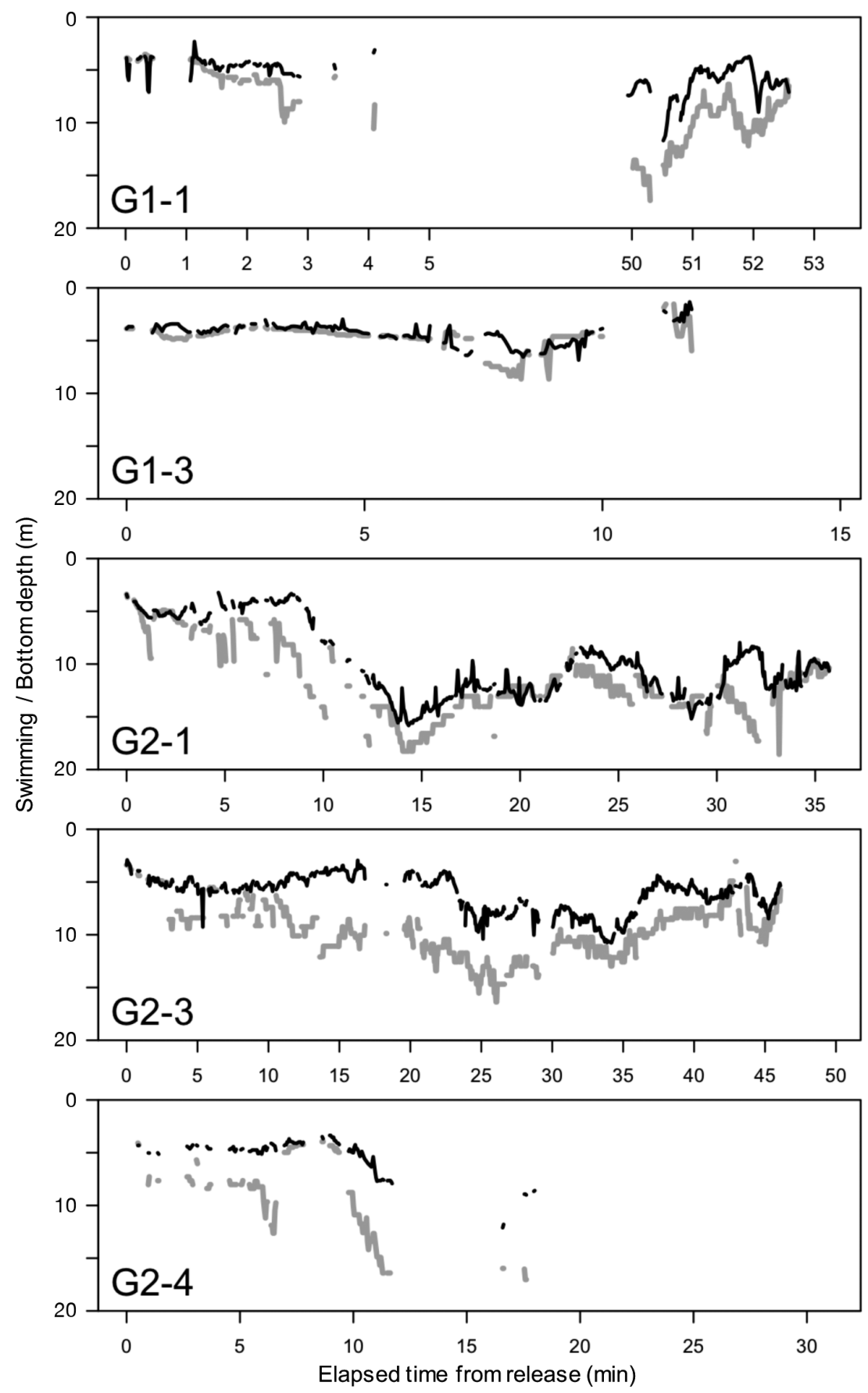

Fig. 5. Bottom depth and swimming depth along the homing routes of 5 black rockfish. Black lines: swimming depth of each fish; grey lines: bottom depth. Fish ID (G1-1, G1-3, G2-1, G2-3, and G2-4) is shown at the bottom left of each figure

\section{DISCUSSION}

\subsection{Cohesive movement}

We found partial support for our hypothesis on cohesive movement. Two tagged black rockfish released in the same group swam together immediately after release (Fig. 4). However, except for this one case, the tagged fish moved independently of the other individuals. Therefore, our hypothesis regarding cohesive movement was not rejected but was not largely supported. G1-3 and G1-4 moved almost side-by-side and took turns leading and following (Fig. 4). Similar to other animals moving together, like king penguins (Nesterova et al. 2014) and pigeons (Biro et al. 2006), black rockfish may have no designated leader when they travel cohesively. It is possible, however, that G1-3 and G1-4 swam together by coincidence; the travelling routes determined by individual navigational abilities or escape behaviour influenced by artificial displacement occasionally overlapped at the beginning. Observations by divers and results obtained from biotelemetry have demonstrated that homing navigation in rockfish begins immediately after release (Carlson et al. 1995, Mitamura et al. 2012); therefore, it is probably difficult to clearly distinguish escape movement from navigational movement. Additionally, in Expt 1, the cohesive movement monitoring period was limited because there was not much time during which 2 or more fish were in the receiver array at the same time; G1-1 and G1-2 left the receiver array once within $\sim 10 \mathrm{~min}, \mathrm{G} 1-3 \mathrm{fin}-$ ished the return trip within $\sim 15 \mathrm{~min}$, and G1-4 left the array within $\sim 40 \mathrm{~min}$ after release (Fig. 2). Nevertheless, the 2 black rockfish did swim synchronously during the initial phase of their journey, albeit briefly.

Smaller adult black rockfish may tend to display greater cohesive movement. In Expt 1, G1-3 and G1-4 displayed synchronous movement (Fig. 4). G1-3 and G1-4 were smaller than G1-1 and G1-2; the former were $2-3 \mathrm{~cm}$ smaller in TL and $\sim 60 \mathrm{~g}$ lighter in BW (Table 1). In the preliminary release experiment, black rockfish initially formed groups of 2-5 individuals after release (Video S1). These individuals were relatively smaller (about 15-18 cm in TL) than the 
Table 4. Proportion (\%) of vertical swimming ranges (distance between tagged fish and the sea bottom, i.e. bottom depth swimming depth) during homing of 5 tagged black rockfish

\begin{tabular}{|lrrrrr|}
\hline \multirow{2}{*}{$\begin{array}{l}\text { Vertical swim- } \\
\text { ming range }\end{array}$} & G1-1 & G1-3 & G2-1 & G2-3 & G2-4 \\
\cline { 2 - 6 } & & & & & \\
\hline$\leq 1 \mathrm{~m}$ & 9.5 & 79.9 & 38.6 & 11.4 & 25.5 \\
$\leq 2 \mathrm{~m}$ & 42.2 & 89.4 & 63.2 & 27.1 & 26.9 \\
$\leq 3 \mathrm{~m}$ & 55.9 & 96.0 & 78.3 & 47.8 & 35.2 \\
$\leq 4 \mathrm{~m}$ & 71.5 & 100.0 & 86.4 & 61.1 & 60.7 \\
$\leq 5 \mathrm{~m}$ & 84.4 & & 90.6 & 72.7 & 64.1 \\
\hline
\end{tabular}

specimens used in the current study. The specimens in the preliminary release experiment and those in the biotelemetry experiment were $>150 \mathrm{~mm}$ in TL and were considered adults (Mio 1960). Juvenile black rockfish form large shoals, whereas the adults tend to be solitary (Harada 1962). Adult black rockfish simultaneously released did not form a group in their homing journey in a previous study conducted by Mitamura et al. (2012). In this study, body size of the specimens was similar to that of the individuals used in the biotelemetry experiment in the current study. In contrast, $<1$ position $\min ^{-1}$ (one position per $\sim 2-$ $6 \mathrm{~min}$ ) was used for analysis due to limitations of the biotelemetry system deployed by Mitamura et al. (2012). Cohesive movement by black rockfish in our study was observed for $\sim 100 \mathrm{~s}$ immediately after release, using high-resolution positioning at a $\sim 2.5 \mathrm{~s}$ interval. Although the black rockfish described by Mitamura et al. (2012) may have moved synchronously immediately after release, those movements were not captured. Evidence regarding whether black rockfish travel in schools or shoals is still unclear. However, the results of the preliminary release experiment and observation of 2 rockfish swimming together briefly suggest that smaller adult black rockfish may school together, at least outside of their mating season.

\subsection{Homing behaviour}

Water currents appeared to have an effect on the movement behaviour of the 5 rockfish that returned to the fishing area after release. Current direction was highly concentrated at the time of release in Expt 1 (3 July 2017), and all 4 G1 individuals moved with the current immediately after release (Fig. 2). In comparison, current direction was not concentrated at the time of release in Expt 2 (6 July 2017), and the 4 G2 individuals moved in various directions after release (Fig. 2). Black rockfish may use olfactory cues for homing from an unfamiliar area (Mitamura et al.
2005). For instance, they move upstream, downstream, and back and forth to infer their homing direction using odour (Mitamura et al. 2012). Movements of the 4 G1 individuals were consistent with earlier predictions. Odour dispersal may be complex at a local scale if local currents regularly shift. Therefore, individuals may detect odour in the changing local currents and change their movement direction in response, at least immediately after release.

Current velocity was different between the 2 stations, even though the stations were less than $90 \mathrm{~m}$ apart (Table 3). There could be 2 reasons accounting for this difference. First, the area including the experimental site contains many islands (Seto Inland Sea; Fig. 1); consequently, the current speed is very rapid and its direction changes in a complicated manner. Second, the release site was in a relatively shallow area inside the small bay, while the fishing area was located in a deeper area outside of the bay (Fig. 1). The feature of the sea area and this local difference between the stations could be one of the reasons why the current differed markedly locally.

The travelling paths of the 5 returning individuals were apparently related to the coastline (Fig. 2) and bottom depth (Fig. 5, Table 4) and were independent of current direction (Table 3). This behaviour implies that they may use visual cues, such as landmarks, while returning, especially the proximity of the groyne. In a previous study, black rockfish exhibited search movement around a release site in an unfamiliar area, and finally returned in a straight path to their original location (Mitamura et al. 2012). The rockfish in this study also travelled tortuously after release and began to move in a more straight path closer to their final destination, which was particularly remarkable in individuals G2-1 and G2-3 (Fig. 2). This movement behaviour was consistent with that observed in a previous study, where the straight-line movement in the final phase of homing was associated with a rocky area or vertical wall in the bay (Mitamura et al. 2012). The final destination to the fishing area of the tagged fish in our study was apparently associated with the coastline, with a comparatively steeper inclination around the groyne (Fig. 2). Although it is unclear if there was a rocky area around the final destination, this steeper geographical feature may have served as a visual landmark, helping the rockfish return to the fishing area. However, for the returning individuals, G1-3, G2-1, and G2-3, a place around the groyne was outside of their home range area. Black rockfish generally have small home ranges in rocky areas (Harada 1962, Mitamura et al. 2009). The estimated home ranges of the homing rockfish approximately covered 
the rocky areas around the floating pier (Fig. 2). However, the home ranges may have been underestimated because they were only estimated using $3 \mathrm{~d}$ of positional data. Rockfish select $1-3$ relatively narrow core areas within their wider home ranges (Jorgensen et al. 2006). As the tagged rockfish may have broader home ranges than those estimated, their actual home ranges might have included the homing path. In addition, rockfish may explore areas outside their home ranges to search for new habitats (Matthews 1990b). Homing individuals may memorise landmarks during their daily life or during exploratory migration. Mitamura et al. (2009) suggested that black rockfish rely on visual cues as well as olfactory cues in familiar areas during homing. The probability of finding landmarks along the sea bottom would be high. Thus, the returning individuals might have used landmarks to navigate back to the fishing area.

Three of the 8 tagged black rockfish did not return to the fishing area during the $3 \mathrm{~d}$ monitoring period. G1-4 and G2-2 left the receiver array and were not detected by the receivers again. They were originally captured about 10-20 m north of the floating pier and next to the floating pier, respectively (Table 1). Other individuals captured in the same place (G1-1, G1-3, and G2-1) returned to the fishing area and stayed there (Fig. 2). In a previous study, several black rockfish (32\% of the specimens) did not exhibit homing behaviour after displacement, while others (24\%) homed for several days after release (Mitamura et al. 2002). In the current study, black rockfish were also found to inhabit certain rocky areas north of the receiver array. G1-4 and G2-2, which left the receiver array, might have settled in another suitable place outside the receiver array or might have returned to the fishing area after the monitoring period. It is also possible that these fish were depredated outside the receiver array. G1-2 settled in an area around the groyne to the north of the fishing area and had a wider home range than that of the returning individuals (Fig. 2, Table 3). This individual was fished relatively far from the floating pier near the groyne (Table 1) and was not localised in the fishing area, suggesting that it had been captured on an excursion from the edge of its home range. It might have returned to its original place, which was not within the fishing area.

\subsection{Conclusions and suggestions for future study}

Using a fine-scale multi-individual simultaneous positioning method, we may have observed cohesive movement by a pair of sympatric conspecific fish with high site fidelity that travelled together briefly immediately after release, although the possibility exists that the fish moved synchronously by chance. Despite the challenges presented by this type of experiment, positional data of better quality and quantity could be obtained by improving the experimental design. Depending on the tagged fish, patchy location data, such as those obtained from individual G2-4 (Fig. 2), makes it difficult to observe cohesive movement. Failure to detect signals due to code collisions is unlikely to happen because the biotelemetry system can simultaneously detect more signals at more precise intervals than those in the present experiment (Takagi et al. 2016). It is possible that the tagged fish swam or stayed near obstacles, which prevented direct propagation of the signals. Alternatively, indirect detection by the receivers may have occurred when a position could not be localised. Further, the detection of a signal by the transmitters could have been influenced by various environmental conditions such as current, tide, ambient noise, and bathymetry (Kessel et al. 2014). The study area had a strong and complected current (Table 3 ) with a relatively large tidal range $(\sim 3.5 \mathrm{~m})$ and steep sea bottom topography (Fig. 1). Therefore, a future experiment should be conducted where there are calm currents and a flat seabed; for example, the artificial bay where Mitamura et al. (2012) previously carried out an experiment. Selection of a more appropriate release site within the receiver array could help in the effort to catalogue the complete journey of the tagged fish, as at least 2 of the returning fish (G1-1 and G1-2) left the receiver array during their trip (Fig. 2). In addition, releasing the tagged fish on a small patch of reef instead of sand might be more appropriate, such that more natural navigational behaviour could be observed. We have discussed the possibility that smaller adult black rockfish may school together. However, using smaller specimens is restricted by the size of the available transmitters. This will depend upon future technological advances in biotelemetry systems. Moreover, monitoring periods would be extended by improvements in transmitter battery life. A small transmitter with a large battery capacity and short signal transmitting interval would promote better studies regarding the cohesive movement of small aquatic animals. Although several issues remain to be addressed for the improvement of this type of research, the present study provides a basis on which future studies on the cohesive movement of travelling fish in the natural environment can be designed and developed, based on finescale positional data. 
Acknowledgements. The authors thank Keisuke Doi, Koki Shimono, Yuki Aoki, Yoshiaki Yasue, Kotaro Tanaka, Tomoya Hori, Ryoma Takeno, Ayako Yokoyama, and Yuya Kato for sampling the specimens and assisting with the fieldwork. The authors also thank Sadaharu Iwasaki, captain of the 'Karanusu-maru', for his long-term support of this experiment. We thank Kenzo Kaifu for lending us the receivers and transmitters. We appreciate the constructive comments on the manuscript offered by 3 anonymous reviewers and Junichi Okuyama. This study was partially funded by JSPS KAKENHI Grant Number JP 17 J10603 (J.T.) and JP 20J01383 (J.T.), and a JST CREST Grant, No. JPMJCR13A5, Japan. The Governor of Hiroshima Prefecture issued the permit to collect fish around Ikuno Island for the purposes of this study. All procedures, including the sampling protocol and the tagging surgery, were approved by the Animal Research Committee of Kyoto University (Permit No. Inf-K17004).

\section{LITERATURE CITED}

Baltazar-Soares M, Eizaguirre C (2017) Animal navigation: the eel's magnetic guide to the Gulf Stream. Curr Biol 27: R604-R606

Batschelet E (1981) Circular statistics in biology. Academic Press, London

*Berdahl A, Westley PA, Levin SA, Couzin ID, Quinn TP (2016) A collective navigation hypothesis for homeward migration in anadromous salmonids. Fish Fish 17: 525-542

Biesinger Z, Bolker BM, Marcinek D, Grothues TM, Dobarro JA, Lindberg WJ (2013) Testing an autonomous acoustic telemetry positioning system for fine-scale space use in marine animals. J Exp Mar Biol Ecol 448:46-56

Biro D, Sumpter DJ, Meade J, Guilford T (2006) From compromise to leadership in pigeon homing. Curr Biol 16: 2123-2128

Carlson HR, Haight RE, Helle JH (1995) Initial behavior of displaced yellowtail rockfish Sebastes flavidus in Lynn Canal, Southeast Alaska. Alsk Fish Res Bull 2:76-80

* Delgado MDM, Penteriani V, Morales JM, Gurarie E, Ovaskainen O (2014) A statistical framework for inferring the influence of conspecifics on movement behaviour. Methods Ecol Evol 5:183-189

'Dell'Ariccia G, Dell'Omo G, Wolfer DP, Lipp HP (2008) Flock flying improves pigeons' homing: GPS track analysis of individual flyers versus small groups. Anim Behav 76: 1165-1172

Espinoza M, Farrugia TJ, Webber DM, Smith F, Lowe CG (2011) Testing a new acoustic telemetry technique to quantify long-term, fine-scale movements of aquatic animals. Fish Res 108:364-371

Gold R (1967) Optimal binary sequences for spread spectrum multi-plexing. IEEE Trans Inf Theory 13:619-621

* Green KM, Starr RM (2011) Movements of small adult black rockfish: implications for the design of MPAs. Mar Ecol Prog Ser 436:219-230

Guzzo MM, Van Leeuwen TE, Hollins J, Koeck B and others (2018) Field testing a novel high residence positioning system for monitoring the fine-scale movements of aquatic organisms. Methods Ecol Evol 9:1478-1488

Harada E (1962) A contribution to the biology of the black rockfish Sebastes inermis Cuvier et Valenciennes. Publ Seto Mar Biol Lab 5:307-361
Hemelrijk CK, Reid DAP, Hildenbrandt H, Padding JT (2015) The increased efficiency of fish swimming in a school. Fish Fish 16:511-521

* Irisson JO, Paris CB, Leis JM, Yerman MN (2015) With a little help from my friends: group orientation by larvae of a coral reef fish. PLOS ONE 10:e0144060

* Jorgensen SJ, Kaplan DM, Klimley AP, Morgan SG, O'Farrell MR, Botsford LW (2006) Limited movement in blue rockfish Sebastes mystinus: internal structure of home range. Mar Ecol Prog Ser 327:157-170

Kessel ST, Cooke SJ, Heupel MR, Hussey NE, Simpfendorfer CA, Vagle S, Fisk AT (2014) A review of detection range testing in aquatic passive acoustic telemetry studies. Rev Fish Biol Fish 24:199-218

Krause J, Ruxton GD (2002) Living in groups. Oxford University Press, Oxford

* Leclercq E, Zerafa B, Brooker AJ, Davie A, Migaud H (2018) Application of passive-acoustic telemetry to explore the behaviour of ballan wrasse (Labrus bergylta) and lumpfish (Cyclopterus lumpus) in commercial Scottish salmon sea-pens. Aquaculture 495:1-12

ㄴong JA, Nelson TA (2013) Measuring dynamic interaction in movement data. Trans GIS 17:62-77

Magurran AE (1990) The adaptive significance of schooling as an anti-predator defence in fish. Ann Zool Fenn 27: $51-66$

*Marras S, Killen SS, Lindström J, McKenzie DJ, Steffensen JF, Domenici P (2015) Fish swimming in schools save energy regardless of their spatial position. Behav Ecol Sociobiol 69:219-226

Matthews KR (1990a) An experimental study of the habitat preferences and movement patterns of copper, quillback, and brown rockfishes (Sebastes spp.). Environ Biol Fishes 29:161-178

*Matthews KR (1990b) A telemetric study of the home ranges and homing routes of copper and quillback rockfishes on shallow rocky reefs. Can J Zool 68:2243-2250

Mio S (1960) Biology of Sebastes inermis Cuvier et Valenciennes. Rec Oceanogr Works Jpn 5:86-97

* Mitamura H, Arai N, Sakamoto W, Mitsunaga Y and others (2002) Evidence of homing of black rockfish Sebastes inermis using biotelemetry. Fish Sci 68:1189-1196

* Mitamura H, Arai N, Sakamoto W, Mitsunaga Y and others (2005) Role of olfaction and vision in homing behaviour of black rockfish Sebastes inermis. J Exp Mar Biol Ecol 322:123-134

Mitamura H, Uchida K, Miyamoto Y, Arai N and others (2009) Preliminary study on homing, site fidelity, and diel movement of black rockfish Sebastes inermis measured by acoustic telemetry. Fish Sci 75:1133-1140

Mitamura H, Uchida K, Miyamoto Y, Kakihara T and others (2012) Short-range homing in a site-specific fish: search and directed movements. J Exp Biol 215:2751-2759

Nathan R, Getz WM, Revilla E, Holyoak M, Kadmon R, Saltz D, Smouse PE (2008) A movement ecology paradigm for unifying organismal movement research. Proc Natl Acad Sci USA 105:19052-19059

Nesterova AP, Flack A, van Loon EE, Marescot Y, Bonadonna F, Biro D (2014) Resolution of navigational conflict in king penguin chicks. Anim Behav 93:221-228

* Partridge BL (1982) The structure and function of fish schools. Sci Am 246:114-123

* Pitcher TJ, Magurran AE, Winfield IJ (1982) Fish in larger shoals find food faster. Behav Ecol Sociobiol 10:149-151

* Portugal SJ, Hubel TY, Fritz J, Heese S and others (2014) 
Upwash exploitation and downwash avoidance by flap phasing in ibis formation flight. Nature 505:399-402

R Core Team (2017) R: a language and environment for statistical computing. R Foundation for Statistical Computing, Vienna

Reynolds BF, Powers SP, Bishop MA (2010) Application of acoustic telemetry to assess residency and movements of rockfish and lingcod at created and natural habitats in Prince William Sound. PLOS ONE 5:e12130

Righton D, Westerberg H, Feunteun E, Økland F and others (2016) Empirical observations of the spawning migration of European eels: the long and dangerous road to the Sargasso Sea. Sci Adv 2:e1501694

Shinomiya A, Ezaki O (1991) Mating habits of the rockfish Sebastes inermis. Environ Biol Fishes 30:15-22

Sumpter DJ (2010) Collective animal behavior. Princeton University Press, Princeton, NJ

Editorial responsibility: Victor Benno Meyer-Rochow, Oulu, Finland

Reviewed by: 3 anonymous referees
Takagi J, Ichikawa K, Arai N, Miyamoto Y and others (2016) Simultaneous identification of multiple signals from phase modulation-coded transmitters for acoustic biotelemetry of fish school. J Adv Mar Sci Technol Soc 22: 5-9

Takagi J, Ichikawa K, Arai N, Miyamoto Y, Uchida K, Shoji J, Mitamura H (2018) Simultaneous observation of intermittent locomotion of multiple fish by fine-scale spatiotemporal three-dimensional positioning. PLOS ONE 13: e0201029

* Ueda H (2012) Physiological mechanisms of imprinting and homing migration in Pacific salmon Oncorhynchus spp. J Fish Biol 81:543-558

Wolfe BW, Lowe CG (2015) Movement patterns, habitat use and site fidelity of the white croaker (Genyonemus lineatus) in the Palos Verdes Superfund Site, Los Angeles, California. Mar Environ Res 109:69-80

Submitted: February 21, 2020

Accepted: October 20, 2020

Proofs received from author(s): February 23, 2021 